\title{
A LEI COMO PAI
}

\section{LAW AS PATER}

DOI: 10.5533/1984-2503-20102302

\section{Nilo Batista}

\section{RESUMO}

Este trabalho discute as relações entre dois saberes: psicanálise e direito penal. Defende a idéia de que para que possam dialogar, há um ponto de partida ineludível, que concebe o sofrimento punitivo como dado essencial da sociabilidade humana. Enfoca o poder do pater, enquanto legitimação do poder punitivo doméstico-senhorial pela perspectiva argumentativa da correção e disciplina.

Palavras-chaves: direito penal psicanálise; correção; disciplina.

\section{RESUMEN}

Este trabajo discute las relaciones entre dos saberes: psicoanálisis y derecho penal. Defiende la idea de que para que puedan dialogar, hay un punto de partida ineludible, que concibe el sufrimiento punitivo como dado esencial de la sociabilidad humana. Enfoca el poder del pater, en cuanto legitimación del poder punitivo doméstico-señorial por la perspectiva argumentativa de la corrección y disciplina.

Palabras-clave: derecho penal, psicoanálisis, corrección, disciplina.

\section{ABSTRACT}

This article covers the relations between psychoanalysis and criminal law. It supports the idea that for them to interact there is an inevitable starting 
point, which conceives the punishing suffering as essential information in human sociability. It focuses the power of pater, as a legitimation of domestic and social punishing power, in the argumentative perspective of correction and discipline.

Key-words: criminal law, psychoanalysis, correction, discipline.

\section{RÉSUMÉ}

Cet article s'intéresse aux relations entre deux savoirs : la psychanalyse et le droit pénal. Y est défendue l'idée selon laquelle le dialogue n'est possible qu'en prenant pour point de départ inéludable la conception de la souffrance punitive en tant que facteur essentiel de la sociabilité humaine. L'on s'intéressera plus particulièrement au pouvoir du pater en tant que légitimation du pouvoir punitif domestique et social à partir de la perspective argumentative du châtiment et de la discipline.

Mots-clés : droit pénal ; psychanalyse ; châtiment ; discipline

Não digo, naturalmente, que me converti naquilo que hoje sou apenas devido à tua influência. Isto seria muito exagerado (e até me sinto atraído por esse exagero). Franz Kafka, Carta a Meu Pai.

Os inúmeros encontros, em distintas circunstâncias históricas, entre os saberes jurídico-penal e médico, compõem uma inconclusa novela de terror, que podemos tentar compreender a partir de duas importantes estações do longo percurso: a inquisição e o positivismo criminológico. A primeira aplicava a pena como cura; o segundo impunha a cura como pena. 
A sanção penal - inexoravelmente um fazer sofrer ${ }^{1}$, pois precisamente caracterizada pela inflição de sofrimento ao condenado através da perda ou restrição de direitos - fora concebida também como "medicina da maldade" por Platão², e esta não foi uma opinião isolada na antiguidade. Contudo, nenhum outro corpus jurídico estaria mais aberto à incorporação de tal concepção do que o direito canônico, responsável pelo surgimento histórico de um novo sujeito culpável, acima do qual o magistrado canônico se colocava como pai e senhor. Assim, ao lado de uma poena vindicativa, que reagia, independentemente de qualquer propósito ou de qualquer outro sentido, à infração da lei ou à perversão da fé, emparelhava-se uma poena medicinalis, atenta ao "melhoramento interior", e que teria sua duração prolongada, subsistindo até a emenda do culpado $^{3}$. A inquisição levaria ao paroxismo esses ingredientes e constituiu um formidável programa salvacionista através da pena, a serviço da "cura" de hereges e mais tarde de bruxas.

Joel Birman descreveu a passagem do registro da salvação, difundido no Ocidente pelo cristianismo, para o registro da cura, próprio da pretensão científica da modernidade ${ }^{4}$. Na segunda metade do século XIV, o meticuloso inquisidor Nicolau Eymerich falava de uma "salvação

1 Nietzsche, Friedrich, Genealogia da Moral, tradução P.C. Souza, São Paulo: Companhia das Letras, 1998, p. 55.

2 Platão, Górgias, trad. M.O. Pulquério, Lisboa, 1997, ed. 70, p. 109. No livro IX de As Leis, na segunda fala do ateniense, as palavras "cura" e "doença" são convocadas a integrar uma fundamentação preventivo-geral da pena (tradução de E. Bini, Bauru, 1999, ed. Edipro, p. 358). Sobre isso ver: Costa, Fausto, El Delito y la Pena en la Historia de la Filosofia, tradução de M.Ruiz-Funes, México: Ed. UTEHA, 1953, p. 9 ss; Jaeger, Werner, Paidéia - a Formação do Homem Grego, tradução de A.M. Parreira, São Paulo: Martins Fontes, 2003, p. 1.300; Romilly, Jacqueline de, La Loi dans la Pensée Grecque, Paris: Ed. Belles Lettres, 1971, p. 179 ss.

${ }^{3}$ Schiappoli, Domenico, Diritto Penale Canonico, em Enciclopedia Pessina, Milão: Ed. Libraria, v. I, 1905, pp. 776 ss; Batista, Nilo, Matrizes Ibéricas do Sistema Penal Brasileiro, Rio de Janeiro: Revan, 2000, p. 163 ss.

${ }^{4}$ Birman, Joel, "A biopolítica na genealogia da psicanálise: da salvação à cura", In História, Ciências, Saúde - Manguinhos, Rio de Janeiro, abr.-jun. 2007, v. 14, no 2, p. 530 ss. 
eterna" que também significava "saúde eterna", já que o radical etimológico é o mesmo: saúde provém "do latim salute - salvação" ${ }^{6} \mathrm{Na}$ bula mediante a qual, duas centúrias depois, o papa Inocêncio VIII admoestava quem pretendesse se opor aos inquisidores Kramer e Sprenger, ele se referia aos procedimentos inquisitoriais como "remédios potentes para prevenir a doença da heresia"7.

Os cirurgiões entraram no sistema penal pela porta da sala de tortura, que era um regulamentado meio de prova para orientar a decisão sobre a potência do remédio a ser ministrado ao réu-paciente. Em seu escrupuloso estudo sobre a tortura na península ibérica, entre os séculos XVI e XVIII, Ana Lúcia Sabadell descobriu que, na falta do cirurgião, carrascos experientes eram valorizados por disporem de "considerável conhecimento médico" ${ }^{\prime}$.

Quem poderia sonhar que um dia técnicas e conhecimentos da medicina se reuniriam numa nova modalidade de execução da pena capital, num patíbulo asséptico que parece uma enfermaria, com adereços que evocam um ato médico? A despeito da contradição entre a morte e o sentido preventivo da sanção medicinal, a execução por injeção letal aproxima cenograficamente pena e cura, embora este réupaciente - seja ele um "herético impenitente e relapso" no século XIV ou um "inimigo-combatente" isolado em Guantánamo - já não tenha cura, ou pelo menos já não a tenha fora da morte.

\footnotetext{
${ }^{5}$ Eymerich, Nicolau, Le Manuel des Inquisiteurs, trad. L. Sala-Molins, Paris, Ed. Mouton, 1973, p. 178.

${ }_{7}^{6}$ Nascentes, Antenor, Dicionário Etimológico Resumido, Rio de Janeiro: Ed. INL, 1966.

7 Kramer, Heinrich e Sprenger, James, Malleus Maleficarum, tradução de P. Froes, Rio de Janeiro: Rosa dos Ventos, 1999 p. 44.

${ }^{8}$ Sabadell, Ana Lucia, Tormenta luris Permissione, Rio de Janeiro: Revan, 2006, p. 354.
} 
Os cirurgiões que, no século XVII, procuravam no corpo dos suspeitos o ponto diabólico - aquele sinal insensível à prospecção com agulhas, com o qual o coisa-ruim marcava na pele seu vassalo ou por onde nele penetrara ${ }^{9}$ - prestavam um importante serviço aos juízes, porém não decidiam. Para que a decisão médica se nivelasse à decisão judicial, praticamente vinculando-a, para que a indicação clínica da alta do paciente se equiparasse à expedição jurisdicional do alvará de soltura $^{10}$, seria preciso esperar pela invenção das medidas de segurança, cujos insumos teóricos seriam febrilmente elaborados ou incorporados pelo positivismo criminológico, a partir do último quartel do século $\mathrm{XIX}^{11}$. Entre esses insumos, exemplificativamente, mencionaremos a loucura moral, a temibilidade, a perigosidade, o estado patológico, a habitualidade, o estado perigoso, a perversão moral, a duração indeterminada, a degeneração etc. O positivismo colocou no proscênio a prevenção, fundada numa perigosidade que podia até mesmo dispensar o delito (perigosidade extradelitual), removeu para a coxia a

\footnotetext{
${ }^{9}$ Mandrou, Robert, Magistrados e Feiticeiros na França do Século XVII, tradução de N. Sevcenko e J. Guinsburg, São Paulo: Editora Perspectiva, 1979, p. 84.

${ }^{10}$ Ou vice-versa. Estudando a legislação brasileira sobre drogas nos anos trinta do século XX, pudemos observar que "incontestavelmente, a alta do paciente não era uma decisão médica e sim uma decisão judicial, assimilável a um alvará de soltura, informada por um parecer médico" (Batista, Nilo, "Política criminal com derramamento de sangue", In DS-CDS, Rio de Janeiro: Editora F. Bastos, 1998, ㄲo 5-6, p. 82).

${ }^{11}$ Sobre isso ver: Nogueira, Ataliba, Medidas de Segurança, São Paulo: Editora Saraiva, 1937; Bruno, Aníbal, Perigosidade Criminal e Medidas de Segurança, Rio de Janeiro: Editora Rio, 1977; Romeo Casabona, Carlos Maria, Peligrosidad y Derecho Penal Preventivo, Barcelona: Bosch, 1986; Reale Ferrari, Eduardo, Medidas de Segurança e Direito Penal no Estado Democrático de Direito, São Paulo: Ed. RT; Donna, 2001; Edgardo Alberto, La Peligrosidad en el Derecho Penal, Buenos Aires, Ed. Astrea, 1978; Machado Alvim, Rui Carlos, Uma Pequena História das Medidas de Segurança, São Paulo: IBCCrim, 1997; Morais Ribeiro, Bruno de, Medidas de Segurança, Porto Alegre: Fabris, 1998; Cobo del Rosal, Manuel (org.), Peligrosidad Social y Medidas de Seguridad, Valência: Editora da Universidade de Valência, 1974.
} 
culpabilidade, e deu início à longa temporada de uma peça em dois atos, cujo título mais expressivo foi Profilaxia Criminal ${ }^{12}$.

Doravante, o magistrado disporia de duas varas: a velha vara da pena, para os culpados, e a nova, da medida de segurança, para os perigosos. Contudo, para brandir esta segunda vara, o magistrado necessitava, imprescindivelmente quando o caso envolvesse a saúde mental do sujeito, de um saber psi, de uma sonda que, a exemplo da agulha em busca do ponto diabólico, pudesse tatear os estratos internos inacessíveis à tosca redução fenomenológica da reconstrução processual-probatória do delito (quando não se tratasse de uma perigosidade extradelitual). Os saberes jurídico-penal e médico passavam a dispor de um aparelho de Estado - intencionalmente, recorremos à categoria difundida por Althusser - onde sua interlocução culminava por decidir concretamente sobre controle e repressão mediante terapias punitivas (ou penas terapêuticas): o manicômio judiciário.

Também estava surgindo uma nova vítima dos sistemas penais, condenada a vagar, qual alma errante e sedada, pelas enfermarias situadas entre a negação total e a redução substancial de sua própria capacidade jurídico-penal, isto é, de sua capacidade de culpabilidade (imputabilidade). Não por acaso, Althusser, num depoimento dramático que o envolvia diretamente, comparou a situação desses zumbis jurídicos à dos desaparecidos, daquelas pessoas que, após uma catástrofe, integram uma estimativa estatística sobre cujo destino ignorase tudo, até mesmo se morreram. "Sob sua pedra sepulcral - escreveu Althusser - ele (o infrator diagnosticado insano) é como um morto para

\footnotetext{
${ }^{12}$ Por exemplo, Aníbal Bruno, op. cit., p. 45. É claro que existiu, e provavelmente ainda exista, a Societé Internationale de Prophylaxie Criminelle.
} 
os que não o visitam, mas quem o visita? (...) Nem morto, nem vivo, não ainda enterrado mas sem obra (...): desaparecido" ${ }^{13}$.

Como a medida de segurança, cuja natureza de verdadeira pena ninguém hoje discute seriamente, era concebida como remédio ${ }^{14}$, não se sujeitava ao princípio da legalidade (o "remédio" não precisa necessariamente estar disponível antes da "doença", bastando que o esteja quando da "terapia") e nem podia ter duração determinada. AssierAndrieu compreende o texto de Althusser como "pedido de acesso à culpabilidade, como se este estado garantisse a manutenção do culpado no sistema de reprodução humana"15. A noção de um direito à culpabilidade atravessa a obra importante e original de Virgílio de Mattos: "todos os cidadãos - proclama ele - devem ser considerados imputáveis, para fins de julgamento penal, com todas as garantias a ele atinentes"16.

Ultrapassa os limites dessa intervenção recordar a imediata e eufórica adesão de vastos setores da psiquiatria e da psicologia ao programa político-criminal do positivismo criminológico. Ao programa, sim, porquanto às pretensões "científicas" de uma Antropologia Criminal viria somar-se rapidamente o anelo investigatório de uma antropometria criminal; das entranhas de uma Psicologia Judiciária surdia a ambição estreita de credenciar-se como uma espécie de técnica detectora de mentiras de testemunhas ou acusados; os capítulos psiquiátricos cresciam a cada nova edição dos manuais de Medicina Legal.

\footnotetext{
13 Althusser, Louis, O Futuro Dura Muito Tempo, tradução de R.F. d'Aguiar, S. Paulo: Companhia das Letras, 1992, p. 29. Para os aparelhos ver: Ideologia e Aparelhos Ideológicos do Estado, tradução de J.J. M. Ramos, Lisboa: Editorial Presença, 1980.

${ }^{14}$ Bettiol recorria a um argumento de Nagler para frisar que o sofrimento imposto ao sujeito perigoso, submetido a medida de segurança, seria equiparável ao sofrimento proveniente de uma intervenção cirúrgica: "simples meio para chegar à cura" (Bettiol, Giuseppe, Direito Penal, trad. P.J. da Costa Jr. e A.S. Franco, S. Paulo: Ed. RT, 1976, v. III, p. 265).

${ }^{15}$ Assier-Andrieu, Louis, O Direito nas Sociedades Humanas, trad. M.E. Galvão, S. Paulo: M. Fontes, 2000, p. 300.

${ }^{16}$ Mattos, Virgilio de, Uma Saída - Preliminares para a Desconstrução das Medidas de Segurança, Rio de Janeiro: Revan, 2006, p. 185.
} 
Certas categorizações nosológicas favoreciam o contubérnio médico-policial. A monomania raciocinante ou afetiva, versada por Pinel e Esquirol, está sendo designada, no último quartel do século XIX em toda a Europa, por loucura moral (folie morale ou raisonnante, moral insanity, moralisch Wahnsinn, pazzia morale): Lombroso, no prefácio à terceira edição de seu mais ambicioso livro, orgulhava-se de ter demonstrado, associando doença a atavismo, a essencial fusão entre seu conceito de criminoso nato e o de louco moral ${ }^{17}$. Uma doença para a qual, como anotou Roberto Machado, "a terapêutica fundamental instituída pela psiquiatria chamou-se justamente tratamento moral ${ }^{18}$ é algo que, transpostos os portões do foro, converte-se num delito para cujo autor inimputável prescrever-se-á uma internação penal até que se constate "cientificamente" sua cura; devemos a Cristina Rauter uma vigorosa denúncia sobre os estragos daquilo que hoje se chama "personalidade psicopática" ou "sociopata" - essa versão psi do "inimigo" jakobsiano - no sistema penal brasileiro ${ }^{19}$.

Num dos mais prestigiosos manuais de Medicina Legal brasileiro da segunda metade do século XX, eram tais sujeitos caracterizados por "procederem sem obediência à lei e sem atenção aos preceitos da ética social"20: essas características convertem a infração em doença, convertem a autonomia moral da pessoa humana num sintoma. Não foi por acaso que o positivismo produziu uma concepção sintomática da

\footnotetext{
${ }^{17}$ Lombroso, Cesare, L'Uomo Delinquente, Turim: Fr. Bocca, 1884, p. IX. Para seus fiadores psiquiátricos, p. 543, nota 1 (ausente Esquirol).

${ }_{18}$ Machado, Roberto et alii, Danação da Norma, Rio de Janeiro: Graal, 1978, p. 391.

${ }^{19}$ Rauter, Cristina, Os Carreiristas da Indisciplina, Rio de Janeiro: Achiamé, 1979; republicado em Criminologia e Subjetividade no Brasil, Rio de Janeiro: Revan, 2003, p. 113 ss.

${ }^{20}$ Gomes, Hélio, Medicina Legal, Rio de Janeiro: F. Bastos, 1963, p. 212.
} 
ação humana ${ }^{21}$, e que ainda hoje penalistas devotos da prevenção especial vejam a ação como "manifestação da personalidade"22.

III

Na metade do século $X X$, constitui um lugar-comum dos manuais de Direito Penal incluir a Psiquiatria Forense e a Psicologia Judiciária no elenco das "disciplinas auxiliares" ${ }^{23}$. Ao contrário, de psicanálise pouco ou nada se fala. Mesmo no campo da Medicina Legal - com a explicável exceção de Júlio Porto Carrero - a recepção do pensamento psicanalítico é tímida e desconfiada: nada além de alguma referência isolada e superficial, como aquela que Leonídio Ribeiro fez a Freud em seus escritos sobre homossexualismo ${ }^{24}$. Em sua Psicopatologia Forense, que uma década depois se converterá ipsis litteris no segundo volume de sua Medicina Legal, Afrânio Peixoto não menciona, nem na bibliografia, Freud; aliás, nem Porto Carrero, nem Arthur Ramos... ${ }^{25}$ Contudo, num livro de 1933, que denominou Criminologia, dedicado a Dom Luis Jiménez de Asúa (um dos principais responsáveis pela vulgarização da psicanálise nos meios jurídico-penais latino-americanos ${ }^{26}$ ), Afrânio Peixoto ensaia uma interlocução, naturalmente perturbada pela distância

\footnotetext{
${ }^{21}$ Sobre ela, Fragoso, Heleno, Conduta Punível, S. Paulo: J. Bushatsky, 1961, p. 11; Ferri, Enrico, Princípios de Direito Criminal, trad. L.L. d'Oliveira, S. Paulo: Saraiva, 1931, p. 274 ss.

${ }^{22}$ Roxin, Claus, Derecho Penal, trad. D.M. Luzón Peña et alii, Madri: Civitas, 1999, p. 252.

${ }^{23}$ Por exemplo, Magalhães Noronha, E., Direito Penal, S. Paulo, 1985, ed. Saraiva, $23^{\mathrm{a}}$ edição, v. I, pp. 17 e 18; Bruno, Aníbal, Direito Penal, Rio de Janeiro: Forense, 1959, v. I, t. 1ํ, p. 45.

${ }^{24}$ Ribeiro, Leonídio, Crimonologia, Rio de Janeiro: Ed. Sul Americana, 1957, v. I, p. 70; do mesmo, De Médico a Criminalista, Rio de Janeiro: Liv. S. José, 1967, p. 237.

${ }^{25}$ Peixoto, Afrânio, Psico-patologia Forense, $2^{2}$ edição, Rio de Janeiro: F. Alves, 1923; Peixoto, Afrânio, Medicina Legal, $3^{\underline{a}}$ edição, Rio de Janeiro: F. Alves, 1931, v. II.

${ }^{26}$ Jiménez de Asúa, Luis, Psicoanálisis Criminal, B. Aires: Depalma, 1982; a primeira edição é de 1940.
} 
dos respectivos procedimentos metodológicos ${ }^{27}$. O mais prestigiado penalista brasileiro do século XX, Nélson Hungria, interditou o diálogo com a psicanálise, valendo-se de fórmula indigna de seu merecimento intelectual $^{28}$.

Sem embargo de inúmeras iniciativas pontuais de penalistas brasileiros na exploração de jazidas psicanalíticas, cujo arrolamento transcenderia o modesto calado da presente intervenção, o fato é que não foram até agora lançadas pontes metodológicas que suportassem um trânsito mais intenso de materiais teóricos com reflexos permanentes na elaboração conceitual e na experiência judiciária do direito penal. Não é difícil perceber as dificuldades que cercam este namoro incapaz de passar ao ato.

Se constatamos divergências de conteúdo até entre categorias jurídicas - como se dá, por exemplo, entre o conceito de funcionário público do direito administrativo e do direito penal, ou entre o conceito de coisa móvel do direito civil e do direito penal - não pode espantar certas radicais diferenças entre categorias centrais de dois saberes a rigor tão distantes quanto direito penal e psicanálise. Tomemos, também como exemplo, a noção de culpa (entendida, juridicamente, como culpabilidade, e não como negligência ou imprudência).

A categoria culpa se inscreve num lugar privilegiado em ambos os saberes, porém com conteúdos e efeitos bem distintos. Na psicanálise a culpa é entendida como sentimento; este sentimento impõe ao sujeito certo sofrimento, para o qual se buscarão caminhos terapêuticos. No

\footnotetext{
${ }^{27}$ Afrânio Peixoto faz do alívio psíquico do infrator por sentimento de culpa um argumento legitimante da pena (p. 144), e despede-se da esquemática exposição de algumas noções da psicanálise assim: "Quaisquer que sejam as nossas críticas e sorrisos a tal ou qual dos detalhes da doutrina de Freud, há no freudismo muito, muitíssimo a considerar" (p. 83). Cf. Criminologia, Rio de Janeiro: Editora Guanabara, 1933.

28 "Errou Freud - o denegridor da espécie humana - quando, nas suas hipóteses sobre 0 inconsciente, viu na psique da criança um volutabro em que se acumulam infâmias e sordícies" - cf. Comentários ao Código Penal, Rio de Janeiro: Forense, 1958, v. I, t. II, p. 363.
} 
direito penal, a culpa é formulada como juízo; uma vez juridicamente constatado, tal juízo autoriza a imposição de sofrimento punitivo ao sujeito. Assim, enquanto a culpa como sentimento mobiliza uma intervenção psicanalítica que pretende atenuar ou curar o sofrimento do paciente, a culpa como juízo de reprovação habilita e legitima o próprio sofrimento punitivo a exercer-se sobre o condenado. "- Não sofras por essa culpa que agora conheces", poderia ser dito ao paciente pelo analista; "- (re)conhecida tua culpa, agora sofrerás", diz o juiz ao réu. Baratta vislumbrou na teoria psicanalítica "uma radical negação do tradicional conceito de culpabilidade e, portanto, também de todo direito penal baseado no princípio da culpabilidade"29.

Para que esses dois saberes - psicanálise e direito penal - possam dialogar, há um ponto de partida ineludível, consistente em conceber o sofrimento punitivo ou como dado essencial da sociabilidade humana, enquanto imperativo ético ou enquanto instrumento utilitário (como fazem as teorias legitimantes da pena, absolutas ou relativas) ou como o mais infecundo e violento modelo jurídico de decisão de conflitos, remanescência do Estado de polícia dentro do Estado de direito, contra o qual conspira para agigantar-se permanentemente, na prática se exercendo sempre de forma seletiva e estigmatizante (como fazem as teorias que deslegitimam a pena). Parece evidente que só a segunda concepção viabilizaria a interlocução entre psicanálise e direito penal, através dela coincididos numa função restauradora e libertária do sujeito.

Mesmo a interlocução entre psicanálise e criminologia, como observa Salo de Carvalho, só é pensável a partir do que ele chama de "criminologia trágica", desencantada do fetiche etiológico cientificista e comprometida com modestas, mas imprescindíveis, estratégias de

\footnotetext{
${ }^{29}$ Baratta, Alessandro, Criminologia Crítica e Crítica do Direito Penal, tradução de J.C. Santos, Rio de Janeiro: Revan, 1999, p. 50.
} 
redução de danos. Para Salo, a possibilidade da interlocução estaria "na convergência dos discursos para a análise crítica do mal-estar contemporâneo que se traduz de inúmeras formas na reprodução das violências" ${ }^{30}$.

\section{IV}

E chegamos, enfim, à chamada "metáfora paterna". É curioso observar que hoje, entre nós, seu alcance e sua circulação nos meios jurídicos e na ciência política são menos questionados do que nos meios psicanalíticos e criminológicos críticos. Podemos vê-la, no denso estudo da jurista Nicolazzi Philippi, como "valor simbólico (...) que discerne, para o sujeito, a possibilidade de projetar-se para além de uma percepção especular e (...) reconhecer a regulação do universo social que o antecede" 31 . De forma peremptória se exprime Guerra Filho: "o significante Pai é equivalente ao significante $L e{ }^{3{ }^{32}}$. O brilhante cientista político Gisálio Cerqueira pretende que "a diluição da figura paterna, sua ausência ou degradação, apontam para o self-service normativo, inviabilizando a prática da democracia" ${ }^{33}$.

Já nos meios psicanalíticos e criminológicos críticos a metáfora paterna parece estar em baixa. Márcia Arán observa que tal interpretação representou "mais um problema que propriamente uma

\footnotetext{
${ }^{30}$ Carvalho, Salo de, "Criminologia e psicanálise: possibilidades de aproximação", In Revista de Estudos Criminais, P. Alegre: Notadez, 2008, no 29, p. 89.

${ }^{31}$ Nicolazzi Philippi, Jeanine, A Lei - uma Abordagem a partir da Leitura Cruzada entre Direito e Psicanálise, B. Horizonte: Ed. Del Rey, 2001, p. 209.

${ }^{32}$ Guerra Filho, Willis Santiago, Sobre a origem metapsicológica da ordem jurídica, mimeo.

${ }^{33}$ Cerqueira Filho, Gisálio, Édipo e Excesso - Reflexão sobre Lei e Política, P. Alegre: Ed. Fabris, 2002, p. 59.
} 
solução" ${ }^{34}$, e Regina Néri interpela a (in)consistência histórica e as funções ocultas da universalização do que chama de "figura legisladora do pai” ${ }^{35}$. Vera Malaguti Batista deparou-se com o uso sistemático da metáfora paterna, por psicólogos e assistentes sociais auxiliares do então Juizado de Menores, na criminalização de jovens infratores afrodescendentes ${ }^{36}$.

Passemos ao largo dessa figura paterna que se pretende identificar com a interdição, deste pai reciclado em lei, para observarmos a mesma metáfora pelo avesso, isto é, uma lei figurada como pai. Para desfrutarmos de todas as virtualidades do deslizamento de sentido que postula transpor para a lei as qualidades do pai, será conveniente uma visita a este personagem histórico suficientemente descrito pelo direito: o pai.

\section{V}

A casa constituiu, desde a antiguidade, e nela ao lado do templo e do palácio, a sede de uma sociedade política chefiada por autoridade investida de ilimitado poder punitivo. Ao lado do sacerdote e do rei, cujas funções aliás desempenhava no âmbito doméstico ${ }^{37}$, o pai dispunha de um feixe de poderes cuja designação jurídica romana revela a desmedida extensão: ius vitae et necis ou vitae necisque potestas, direito-poder de vida e de morte. O pater podia privadamente encarcerar,

\footnotetext{
${ }^{34}$ Arán, Márcia, "A singularização adiada: o feminismo na civilização moderna", In Birman, Joel (org.), Feminilidades, Rio de Janeiro: Contra Capa, , 2002, p. 68.

${ }^{35}$ Néri, Regina, Enfraquecimento da lei ou aumento do poder punitivo? mimeo, p. 14.

${ }^{36}$ Batista, Vera Malaguti S.W., Difíceis Ganhos Fáceis - Droga e Juventude Pobre no Rio de Janeiro, Rio de Janeiro: Revan, 2003.

37 "A família romana (...) tinha seus sacra, ou seja, seu culto especial, e o paterfamilias era seu sacerdote. Ele era também juiz dos filiifamilias" (Bonfante, Pedro, Instituciones de Derecho Romano, trad. L.Bacci e A. Larrosa, Madri: Réus, 1965, p. 160).
} 
pelo tempo que lhe aprouvesse, seus filhos; podia açoitá-los; impor-lhe grilhões para o trabalho na lavoura; vendê-los e matá-los.

Esses poderes atravessam, no direito romano, quase incólumes, os períodos chamados antigo e clássico, para, na época helênica, serem restringidos pela perspectiva argumentativa da correção e disciplina ${ }^{38}$. Uma das conseqüências do poder paternal em Roma foi aquela dilatação da adolescência (que, começando aos 14 anos, quando terminava a pueritia que principiara aos 7 , chegava aos 28) e da iuventus (que alcançava os 45 ou mesmo os 50 anos): nas palavras de Fraschetti, "como se a adolescência e a juventude fossem idades prorrogadas de maneira fictícia com o objetivo de evidenciar a continuação da submissão dos filhos aos pais, detentores efetivos de todos os poderes" ${ }^{39}$.

Se visitarmos o século XI francês, na companhia de Duby, encontraremos ao lado da justiça real o que ele chamou de "justiça doméstica". A casa, essa "institution primordiale", está sob a direção "exclusive et absolue d'un chef", que tem direito à obediência de todos (esposa, filhos, netos e respectivas esposas, clientes, escravos e outros dependentes): "ele ordena e ele castiga com toda a liberdade". "Le chef ici dicide", nessa justiça essencialmente repressiva, onde o pai-chefe exerce "son droit de punir" 40.

Quando, nos próximos séculos, iniciar-se o processo histórico que, pela acumulação primitiva de poder punitivo (sem a qual não se viabilizariam os futuros Estados nacionais), culminará na invenção da pena pública, não é apenas a vítima que terá confiscado seu conflito: a

${ }^{38}$ Bonfante, op. cit., pp. 162-163. Segundo Marciano, o imperador Adriano condenou ao internamento numa ilha certo pai que matara o filho por manter relações sexuais com a madrasta; embora o texto proclame que "o pátrio poder não deve consistir em atrocidade", o fundamento da condenação residiu em ter sido o filho morto "antes como ladrão do que com o direito de pai (quod latronis magis, quam patris iure eum interfecit)"; cf. D. XLVIII, IX, 5.

${ }^{39}$ Fraschetti, Augusto, "O mundo romano", In Levi, G. e Schmitt, J.C., História dos Jovens, trad. C. Marcondes et al., S. Paulo: Companhia das Letras,, 1996, v. I, p. 71.

${ }^{40}$ Duby, Georges, La justice et le juge aux temps féodaux, no volume La Justice, Centre de Sciences Politiques de l'Institut d'Etudes Juridiques de Nice, Paris: PUF, 1961, p. 219 ss. 
pena pública é construída também à custa do pater, espoliado em nacos substanciais de seu poder punitivo.

Na metade do século XV, Afonso V de Portugal reitera que "ao Rei, ou Príncipe da terra, pertence somente fazer e ter cárcere (...) e qualquer outro, que por si faz cárcere privado, contradiz ao Rei ou Príncipe da terra". Contudo, ao final da lei que monopolizava o encarceramento então, como anteriormente, de natureza apenas processual-cautelar ("parar reter e guardar [...] os malfeitores e fazer em eles execução") e não penal - o soberano ressalva o caso daquele "que encarcerar seu servo, ou filho para os castigar d'algumas más manhas e costumes que houverem" ${ }^{\prime 1}$. Nessa passagem, a legitimação do poder punitivo doméstico-senhorial pela perspectiva argumentativa da correção e disciplina já aparece com clareza.

Nélson Hungria constata a longa duração desse poder punitivo observando que "os códigos do século XIX, na sua maioria, não cuidavam especialmente dos maus tratos ou castigos imoderados, de modo que estes só se tornavam puníveis quando ocasionassem lesão corporal ou morte" ${ }^{\prime 2}$. Na prática, seria preciso também que o fato fosse comunicado a uma autoridade pública, o que estava muito longe de ser freqüente.

Nosso Código Criminal de 1830 contemplava, entre as causas de justificação do crime, a hipótese de consistir ele "no castigo moderado que os pais derem a seus filhos, os senhores a seus escravos e os mestres a seus discípulos" 43 . O Conselheiro Paula Pessoa referendava as penas domésticas advertindo que "na primeira idade da vida e na

\footnotetext{
${ }^{41}$ Ordenações Afonsinas, V, LXXXXII. De modo geral, só o casamento subtraía o filho ao poder punitivo paterno: "segundo estilo de nosso Reino, sempre como o filho é casado, é havido por emancipado, e fora do poder de seu pai" (Or. Fil., I, LXXXVIII, 6).

${ }^{42}$ Comentários ao Código Penal, cit., v. V, p. 447.

${ }^{43}$ Código Criminal de 1830, art. 14, § 60.
} 
adolescência é preciso a luta com as paixões nascentes"44. E Vieira de Araújo ponderava que submeter à Justiça criminal os abusos do pátrio poder "desmoralizaria a autoridade paterna, perturbando as relações domésticas" ${ }^{45}$.

À procura de meninas e senhoras novecentistas na literatura brasileira, Helena Bocayuva deparou-se com uma curiosa tarefa das segundas: amenizar, tanto quanto possível, "a severidade do paterfamilias, muitas vezes extremamente autoritário e até cruel com sua prole" ${ }^{46}$. Ao "absolutismo onipotente deste paterfamilias" referiram-se Gizlene Neder e Gisálio Cerqueira Filho, num instigante estudo em que a violência familiar é experimentada como antecedente do fracasso das políticas de atendimento e do extermínio da infância e adolescência pobres brasileiras ${ }^{47}$.

Não nos deteremos sobre o dado infraestrutural que, no Brasil, prolongou - juridicamente, até 1888, e culturalmente só Deus saberá até quando - o poder punitivo doméstico-senhorial: o escravismo, que pressupõe e depende do exercício permanente e aterrorizador desse poder. Sobre isso, a partir da circunstância constrangedora de termos fundado a pena pública no apogeu do poder punitivo privado patriarcal, detivemo-nos extensamente em outra ocasião ${ }^{48}$.

O retrato jurídico do pater estaria incompleto sem uma circunstância histórica desconcertante. Na tradição romana, paterfamilias é aquele que

\footnotetext{
${ }^{44}$ Paula Pessoa, Cons. Vicente Alves de, Código Criminal do Império do Brazil, Rio de Janeiro: Ed. A.A. Cruz Coutinho, 1885, p. 60.

${ }^{45}$ Vieira de Araújo, João, Código Criminal Brasileiro, Recife: Ed. J. Nogueira de Souza,1889, p. 297.

${ }^{46}$ Bocayuva, Helena, Sexualidade e Gênero no Imaginário Brasileiro, Rio de Janeiro: Revan, 2007, p. 106.

${ }^{47}$ Neder, Gizlene e Cerqueira Filho, Gisálio, Os filhos da lei, em Idéias Jurídicas e Autoridade na Família, Rio de Janeiro: Revan, 2007, p. 107 ss. (esp.110, 128 e passim).

${ }^{48}$ Batista, Nilo, "Pena pública e escravismo", In Arquivos do Ministério da Justiça, Brasília: Min. Justiça, 2006, ano 51, no 190, pp. 211 ss.
} 
não tem outro ascendente vivo por linha masculina ${ }^{49}$. Se é certo que a morte do pater implica sua reprodução (pela divisão da família original em tantas quantos sejam os filhos varões, doravante cada qual deles chefe absoluto de uma nova família), não é menos certo que a condição jurídica de pater supõe a morte do pai; ou, dito de outra forma, juridicamente todo pater é um órfão. A suposição de Freud, de que "ao parricídio seguiu-se prolongada época na qual os irmãos disputavam a sucessão paterna"50, foi resolvida pelo direito romano no sentido da preservação e multiplicação do poder punitivo paterno.

\section{VI}

Podemos agora, recuperada a imagem jurídica do pai, compreender os motivos pelos quais Raúl Zaffaroni caracteriza como "paternalista" o Estado policial, que aposta no castigo e no adestramento dos súditos e tem a pretensão de protegê-los até contra suas próprias ações autolesivas $^{51}$, como se dá na criminalização de usuários de drogas ilícitas, e os motivos pelos quais Hassemer vê o Estado "converter-se em pai" nas expectativas de setores fascitizados da classe média europeia que demandam mais invasividade policial através de escutas ${ }^{52}$.

A identificação, como se vê, não se realiza propriamente na paternidade, mas sim na autoridade investida de poder punitivo, à qual tocaria desempenhar-se como legislador, juiz e verdugo dos próprios filhos. Entre nós, por causa do escravismo, este poder punitivo teve reconhecimento jurídico até o final do século XIX, e extensa

\footnotetext{
${ }^{49}$ Sobre esse aspecto, cf. Bonfante, op. cit., p. 158.

${ }^{50}$ Freud, Sigmund, "Moises y la Religion Monoteísta", In Obras Completas, trad. L.L.-B. Torres, Madri: Ed. Biblioteca Nueva, 1973, t. III, p. 3.290.

${ }^{51}$ Zaffaroni, Raúl et alii, Direito Penal Brasileiro, Rio de Janeiro: Revan, 2003, v. I, p. 94.

52 Hassemer, Winfried, Direito Penal Libertário, trad. R. Greve, B. Horizonte: Editora Del Rey, 2007, p. 238.
} 
sobrevivência cultural. A lei como pai é uma lei muito dura, ao contrário de doces idealizações construídas de costas para a história.

Olhando para ele, após sua estupenda aventura histórica, o pai ao qual se refere a lei é alguém caracterizado pelo poder de castigar, pelo poder de dirigir-se aos filhos não por conselhos - recorramos à distinção de Hobbes $^{53}$ - mas por ordens às quais os mesmos filhos devem obediência.

Nos chamados "discursos de cadafalso", não era raro que os padecentes responsabilizassem seus pais, ou o abandono deles, pelo destino que lhes tocara ${ }^{54}$. De certa forma, esse enunciado colocava o pai simbolicamente ao lado do carrasco.

Kafka, como se vê na epígrafe desta intervenção, tomava esse determinismo por um exagero, que, aliás, o atraía. Muito mais exagerado é acreditar numa função mecanicisticamente motivadora da lei, acreditar que o homem se comporta pavlovianamente segundo a proibição ou o mandado. Nosso Ministro da Saúde, a propósito da assim chamada "lei seca", declarou que "a sociedade estava precisando de um pai" ${ }^{35}$. A principal utilidade dessa superstição é sua subjetivação normativa, da qual proviria, para usar palavras de Binding, "deveres de obediência ou de submissão (Pflichten des Gehorsams oder Botmässigkeit)" ${ }^{, 56}$ capazes de produzir, a baixo custo político, providenciais estoques de poder punitivo.

Despir o pai de poder punitivo, desse arcaico fardo que the foi imposto, pode ser um ponto de partida para afastar dele, e da lei, a imposição de sofrimento no qual se confundiram. Psicanálise e direito penal dialogarão mais facilmente em torno da oposição desejo-liberdade,

\footnotetext{
${ }^{53}$ Hobbes, Thomas, Leviatã, trad. H.G. Burati, S. Paulo: Rideel, 2005, p. 156.

${ }^{54}$ Por exemplo, cf. Sanson, H., Mémoires des Sanson, Paris: Ed. Dupray de la Mahérie, t. VI, 1863, p. 332.

${ }^{55}$ Cf. Folha de São Paulo, 10.ago.08, p. C8.

${ }^{56}$ Binding, Karl, Die Normen und ihre Übertretung, ed. facsimilar Scientia, 1965, v. I, p. 96.
} 
que sinaliza um conflito juridicamente solucionável, do que aferrados à oposição desejo-interdição, que chama poder punitivo. O milenar percurso da horda não foi agitado por subsequentes remoções ou ressignificações de interdições?

A (re)privatização de poder punitivo que o novo modelo de acumulação capitalista propõe não aposta muitas fichas no pai; poderá finalmente o velho e trágico personagem libertar-se das cruéis funções que Ihe tocaram? Ou estará condenado perpetuamente ao fazer sofrer que é o núcleo aterrador do poder punitivo? Nossa capacidade de prever um outro mundo depois do grande encarceramento em curso pode depender de nossa capacidade de renunciar a metáforas que realimentam o princípio da punição, ou seja, o princípio - jamais demonstrado! - segundo o qual a imposição de sofrimento previne transgressões ou restaura a ordem virtuosa violada. 